\title{
Apoptosis of human gastric cancer SGC-7901 cells induced by podophyllotoxin
}

\author{
CHEN-FENG JI ${ }^{1,2}$ and YU-BIN JI ${ }^{1,2}$ \\ ${ }^{1}$ Engineering Research Center of Natural Anticancer Drugs, Ministry of Education; \\ ${ }^{2}$ Center of Research on Life Science and Environmental Science, Harbin University of Commerce, Harbin, \\ Heilongjiang 150076, P.R. China
}

Received November 6, 2013; Accepted February 26, 2014

DOI: $10.3892 /$ etm.2014.1606

\begin{abstract}
Numerous studies have demonstrated that podophyllotoxin and its derivatives exhibit antitumor effects. The aim of the present study was to investigate SGC-7901 cell apoptosis and the underlying mechanism induced by podophyllotoxin. SGC-7901 cells were treated with varying concentrations of podophyllotoxin. MTT assays and flow cytometry were used to evaluate the effects of podophyllotoxin on the proliferation and apoptosis of SGC-7901 cells, while fluorescence inverted microscopy was used to observe the morphology of SGC-7901 cells that had been dyed with Hoechst 33258. In addition, laser scanning confocal microscopy was used to analyze the mitochondrial membrane potential (MMP) of SGC-7901 cells dyed with Rhodamine 123. Western blotting was performed to analyze the expression levels of cytochrome $c$ (cyt-c), caspase-9 and caspase- 3 in the SGC-7901 cells. The results indicated that podophyllotoxin was capable of inhibiting growth and inducing the apoptosis of SGC-7901 cells in a dose-dependent manner, causing cell cycle arrest at the $\mathrm{G}_{2} / \mathrm{M}$ phase. After $48 \mathrm{~h}$ of treatment, the apoptotic morphology of SGC-7901 cells was clear, exhibiting cell protuberance, concentrated cytoplasms and apoptotic bodies. Following $24 \mathrm{~h}$ of treatment, the MMP of the SGC-7901 cells decreased. In addition, after $48 \mathrm{~h}$, the expression of cyt- $c$ was shown to be upregulated, while the expression levels of pro-caspase-9 and pro-caspase-3 in the SGC-7901 cells were shown to be downregulated. In conclusion, apoptosis can be induced in SGC-7901 cells by podophyllotoxin, potentially via a mitochondrial pathway, indicating that podophyllotoxin may be a potent agent for cancer treatment.
\end{abstract}

Correspondence to: Dr Yu-Bin Ji, Center of Research on Life Science and Environmental Science, Harbin University of Commerce, 138 Tongda Street, Harbin, Heilongjiang 150076, P.R. China

E-mail: smilejcf001@sina.com

Key words: human gastric cancer, podophyllotoxin, apoptosis, mechanism

\section{Introduction}

Gastric cancer (GC) is one of the most common cancers worldwide, particularly in East Asia and East Europe. Furthermore, the incidence and mortality rates of GC are high, accounting for 1,000,000 mortalities annually. Therefore, GC is a significant problem in terms of global health (1). Despite advances in surgery and chemotherapy for colon cancer, the outcomes of anticancer therapy remain unsatisfactory, thus, further improvements are required. A number of pharmacological experiments have demonstrated that numerous naturally active components, isolated from plants and herbs, exhibit antitumor effects and may be potent agents for cancer treatment $(2,3)$.

Podophyllotoxin is a lignan extracted from the Podophyllum plant, with a molecular formula of $\mathrm{C}_{22} \mathrm{H}_{22} \mathrm{O}_{8}$ and a molecular weight of $414 \mathrm{Da}$. This compound and its derivatives have great significance as antineoplastic drugs and antiviral agents due to the biological activities that they exhibit. Podophyllotoxin and its derivatives are currently used in chemotherapy for various cancer types, including cervical carcinoma, osteosarcoma, nasopharyngeal carcinoma, colon cancer, breast cancer, prostate cancer, testicular carcinoma, small cell lung cancer and lymphoma (4-8). However, studies investigating the antitumor effect on GC are limited (9) and the molecular mechanism remains unclear. In the present study, the inhibition of cell growth and apoptosis induced by podophyllotoxin was investigated in the human GC SGC-7901 cell line, and the underlying mechanism was studied through the mitochondrial pathway.

\section{Materials and methods}

Reagents. Podophyllotoxin, MTT, propidium iodide (PI), Hoechst 33258 and Rodamine 123 were all purchased from Sigma-Aldrich (St. Louis, MO, USA). Hydroxycamptothecin (HCPT) was purchased from Harbin Shengtai Pharmaceutical Co., Ltd. (Harbin, China); RPMI 1640 culture medium was purchased from Thermo Fisher Scientific Inc. (Waltham, MA, USA); fetal bovine serum (FBS) was obtained from Hangzhou Sijiqing Biological Engineering Materials Co., Ltd. (Hangzhou, China) and trypsin was purchased from Gibco-BRL (Rockville, MD, USA). Additionally, mouse antihuman $\beta$-actin, cytochrome c (cyt-c), caspase-9 and caspase-3 
polyclonal antibodies, alkaline phosphatase (AP)-conjugated goat anti mouse polyclonal antibody, SDS-PAGE sample loading buffer, blocking buffer, TBST, buffer5-bromo-4chloro-3-indolyl-phosphate (BCIP)/nitroblue tetrazolium (NBT) alkaline phosphatase color development kit (Beyotime Institute of Biotechnology, Haimen, China); detergent-compatible protein assay kit (Bio-Rad, Hercules, CA, USA).

Apparatus. The CKX 41 inverted fluorescence microscope was purchased from Olympus (Tokyo, Japan) and the mini electrophoresis meter and microplate reader were purchased from Bio-Rad (Hercules, CA, USA). The EPICS XL flow cytometer was purchased from Beckman Coulter (Brea, CA, USA); the SP2 laser confocal scanning microscope was purchased from Leica (Solms, Germany) and the CO-150 $\mathrm{CO}_{2}$ incubator was purchased from New Brunswick Scientific (Edison, NJ, USA).

Cell culture. The human GC SGC-7901 cell line was provided by the Center of Research and Development on Life Sciences and Environmental Sciences of Harbin University of Commerce (Harbin, China). SGC-7901 cells were grown in RPMI 1640 culture medium containing 10\% heat-inactivated FBS at $37^{\circ} \mathrm{C}$ in a humidified atmosphere of $5 \% \mathrm{CO}_{2}$.

Antitumor activity of podophyllotoxin on SGC-7901 cells. Exponentially growing cells were washed, digested with trypsin and suspended in RPMI 1640 medium until a concentration of $1 \times 10^{5}$ cells $/ \mathrm{ml}$ was achieved. In a 96 -well plate, $100 \mu \mathrm{l}$ cell suspension per well was cultured for $24 \mathrm{~h}$. The cells were subsequently incubated with varying concentrations of podophyllotoxin for a further $72 \mathrm{~h} ; 12$ wells were used per concentration. Cells incubated with only $100 \mu 1$ RPMI 1640 culture medium served as a control group. MTT was dissolved in phosphate-buffered saline (PBS) to provide a solution with a final concentration of $0.5 \mathrm{mg} / \mathrm{ml}$. After $72 \mathrm{~h}$, the cell suspension was discarded and $200 \mu \mathrm{l}$ MTT solution $(0.5 \mathrm{mg} / \mathrm{ml})$ was added to each well and incubated at $37^{\circ} \mathrm{C}$ for $4 \mathrm{~h}$. All media were removed and $150 \mu \mathrm{l}$ dimethyl sulfoxide was added to each well in order to dissolve the purple formazan crystals. The plate was agitated for $3 \mathrm{~min}$ and the spectrophotometric absorbance at $570 \mathrm{~nm}$ was measured using a microplate reader. The inhibitory rate and $\mathrm{IC}_{50}$ was calculated.

Effect of podophyllotoxin on cell cycle and apoptosis of SGC-7901 cells. Cells $\left(5 \times 10^{4} / \mathrm{ml} ; 1 \mathrm{ml}\right)$ were planted in 24-well plates and cultured for $24 \mathrm{~h}$ with three wells per group. Subsequently, the cells were treated with various drug concentrations for $48 \mathrm{~h}$. The cells were harvested via trypsinization, washed twice with cold PBS and fixed in 70\% cold ethanol for $12 \mathrm{~h}$ at $4^{\circ} \mathrm{C}$. The fixation fluid was then discarded and the cells were washed with PBS twice. PI was added to the samples for 30 min for staining and the samples were measured by flow cytometry with an excitation wavelength of $488 \mathrm{~nm}$.

Effect ofpodophyllotoxin on the morphologyofSGC-7901 cells. Cells $\left(5 \times 10^{4} / \mathrm{ml} ; 1 \mathrm{ml}\right)$ were planted in 6 -well plates, cultured for $24 \mathrm{~h}$ and treated with varying drug concentrations for $48 \mathrm{~h}$. Cells were harvested via trypsinization, washed twice with cold PBS and fixed in 4\% paraformaldehyde for $30 \mathrm{~min}$ at $4^{\circ} \mathrm{C}$. The fixation fluid was then discarded and the cells were washed with PBS twice. Hoechst 33258 was added for $20 \mathrm{~min}$, after which the dye was discarded and the cells were washed twice with PBS. The cells were observed using an inverted fluorescence microscope.

Effect of podophyllotoxin on the mitochondrial membrane potential (MMP) in SGC-7901 cells. Cells $\left(5 \times 10^{4} / \mathrm{ml} ; 1 \mathrm{ml}\right)$ were planted in 6-well plates, cultured for $24 \mathrm{~h}$ and treated with various drug concentrations for $24 \mathrm{~h}$. Cells were harvested via trypsinization, washed twice with cold PBS and loaded with Rhodamine $123(5 \mu \mathrm{g} / \mathrm{ml})$ for $30 \mathrm{~min}$ at $37^{\circ} \mathrm{C}$. The fluorescence intensity of the MMP was observed using laser scanning confocal microscopy.

Effect of podophyllotoxin on the expression of cyt-c, pro-caspase-9 and pro-caspase-3 in SGC-7901 cells. Cells $\left(5 \times 10^{4} / \mathrm{ml} ; 1 \mathrm{ml}\right)$ were planted in 6 -well-plates, cultured for $24 \mathrm{~h}$ and subsequently treated with varying concentrations of podophyllotoxin for $48 \mathrm{~h}$. Cytoplasm extracts were prepared with $150 \mu \mathrm{l}$ cell lysis buffer on ice for $30 \mathrm{~min}$. Following centrifugation at $10,000 \mathrm{xg}$ at $4^{\circ} \mathrm{C}$ for $10 \mathrm{~min}$, the supernatant was collected and the protein concentration was quantified using the detergent-compatible protein assay kit. Proteins were mixed with SDS-PAGE sample loading buffer (Beyotime Institute of Biotechnology). In total, a 40- $\mu \mathrm{g}$ sample of protein was separated in a $10 \%$ polyacrylamide gel and blotted on a nitrocellulose membrane. The blots were blocked with blocking buffer for $2 \mathrm{~h}$ at room temperature and incubated with anti-cyt- $c$, anti-caspase- 9 and anti-caspase-3 antibodies for $12 \mathrm{~h}$ at $4^{\circ} \mathrm{C}$. Subsequently, the nitrocellulose membranes were washed with TBST buffer three times and incubated with AP-conjugated goat anti-mouse antibody in blocking buffer for $2 \mathrm{~h}$ at R.T. Then the nitrocellulose membranes were washed with TBST buffer three times and detected by BCIP/NBT alkaline phosphatase color development kit (Beyotime Institute of Biotechnology). The bands were then visualized and quantified using the Gel Doc XR imaging system (Bio-Rad, Hercules, CA, USA).

Statistical analysis. Data are expressed as the mean \pm SD. Statistical analyses were performed using analysis of variance to compare the various groups. SPSS 15.0 software was used for statistical analysis (SPSS, Inc., Chicago, IL, USA). P $<0.05$ was considered to indicate a statistically significant difference.

\section{Results}

Antitumor activity of podophyllotoxin on SGC-7901 cells. The MTT assay revealed that following treatment with various concentrations of podophyllotoxin for $72 \mathrm{~h}$, podophyllotoxin exhibited an inhibitory effect on the proliferation of SGC-7901 cells in a concentration-dependent manner. The optical density values of the treated groups exhibited statistically significant differences when compared with the control group $(\mathrm{P}<0.01)$. The $\mathrm{IC}_{50}$ was $26.30 \mu \mathrm{mol} / 1$ (Fig. 1).

Effect of podophyllotoxin on the cell cycle and apoptosis of SGC-7901 cells. Following treatment with varying concentrations of podophyllotoxin for $48 \mathrm{~h}$, the cell cycle changed and 
Table I. Effect of podophyllotoxin on the cell cycle of SGC-7901 cells (3 wells).

\begin{tabular}{lcccc}
\hline & & \multicolumn{3}{c}{ Cell cycle $(\%)$} \\
\cline { 3 - 5 } Group & Concentration $(\mu \mathrm{mol} / \mathrm{l})$ & $\mathrm{G}_{0} / \mathrm{G}_{1}$ & $\mathrm{~S}$ & $\mathrm{G}_{2} / \mathrm{M}$ \\
\hline Control & 0.00 & $65.166 \pm 0.125$ & $26.754 \pm 0.114$ & $14.080 \pm 1.074$ \\
Podophyllotoxin & 26.30 & $43.049 \pm 0.102^{\mathrm{b}}$ & $23.526 \pm 0.081^{\mathrm{a}}$ & $22.425 \pm 0.202^{\mathrm{b}}$ \\
& 52.60 & $34.737 \pm 0.082^{\mathrm{b}}$ & $18.004 \pm 0.142^{\mathrm{b}}$ & $27.259 \pm 0.736^{\mathrm{b}}$ \\
HCPT & 55.00 & $32.210 \pm 0.043^{\mathrm{b}}$ & $45.137 \pm 1.168^{\mathrm{b}}$ & $22.653 \pm 0.086^{\mathrm{b}}$ \\
& 13.15 & $55.351 \pm 0.096^{\mathrm{a}}$ & $24.464 \pm 0.107$ & $18.185 \pm 0.671^{\mathrm{a}}$ \\
\hline
\end{tabular}

Values are expressed as the mean $\pm \mathrm{SD}$. ${ }^{\mathrm{a}} \mathrm{P}<0.05$, vs. control; ${ }^{\mathrm{b}} \mathrm{P}<0.01$, vs. control. HCPT, hydroxycamptothecin.

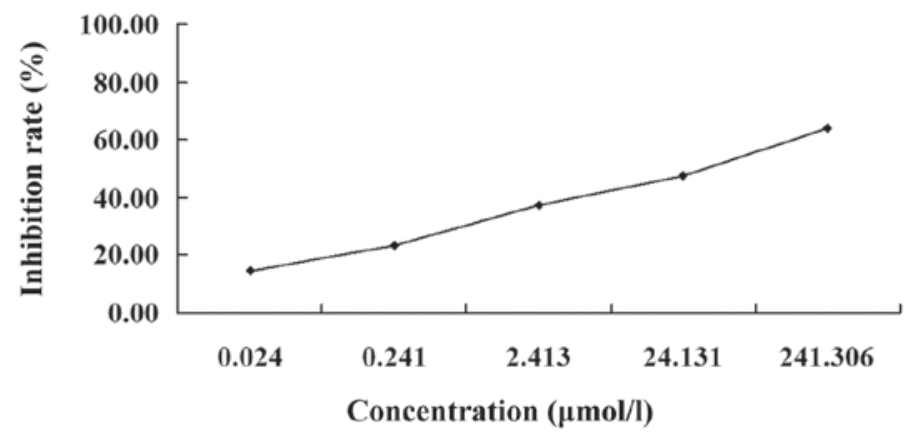

Figure 1. Inhibitory rate of podophyllotoxin on SGC-7901 cells.

A

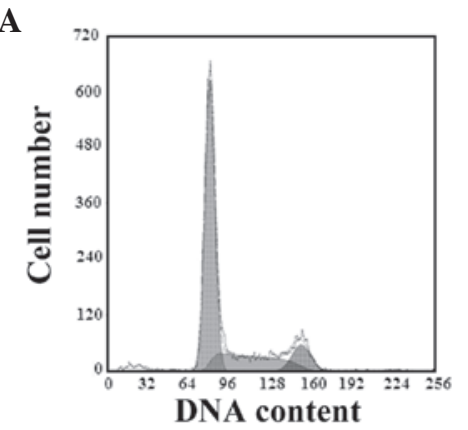

B

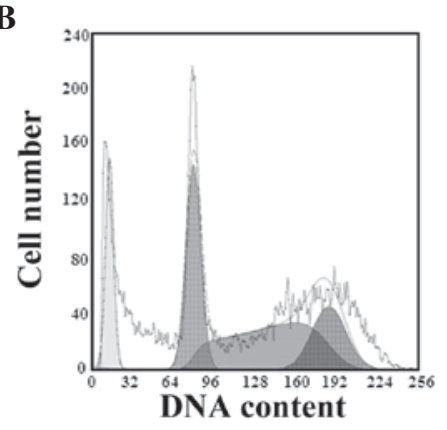

C

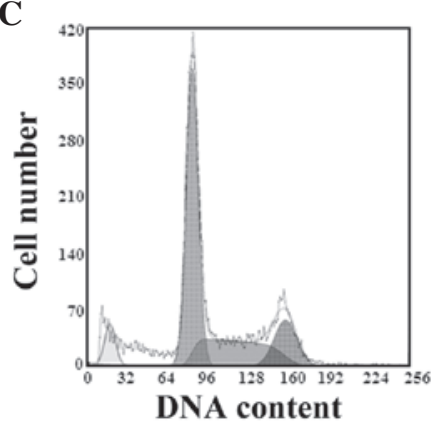

D

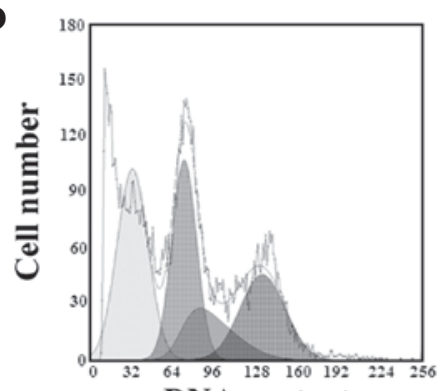

DNA content
$\mathbf{E}$

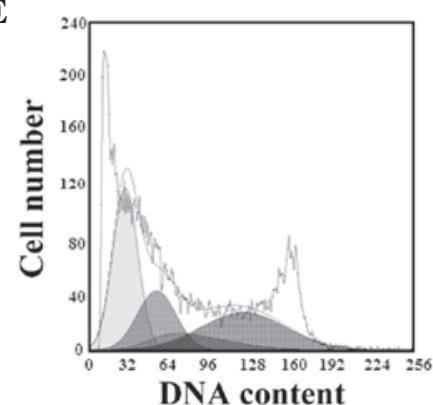

Figure 2. Effects of podophyllotoxin on the apoptosis of SGC-7901 cells treated with (A) negative control, (B) $13.15 \mu$ mol/1 podophyllotoxin, (C) $26.30 \mu$ mol/1 podophyllotoxin, (D) $52.60 \mu \mathrm{mol} / 1$ podophyllotoxin and (E) $55 \mu \mathrm{mol} / 1 \mathrm{HCPT}$ as a positive control. HCPT, hydroxycamptothecin.

the number of cells in the $\mathrm{G}_{0} / \mathrm{G}_{1}$ and $\mathrm{S}$ phases decreased, while the number of cells in the $G_{2} / M$ phase increased. The apoptotic peaks appeared gradually in a concentration-dependent manner, and the apoptosis rates were 11.06, 20.39 and $33.67 \%$ in the $13.15,26.30$ and $52.60 \mu \mathrm{mol} / 1$ podophyllotoxin groups, respectively, as shown in Table I and Fig. 2. 
A

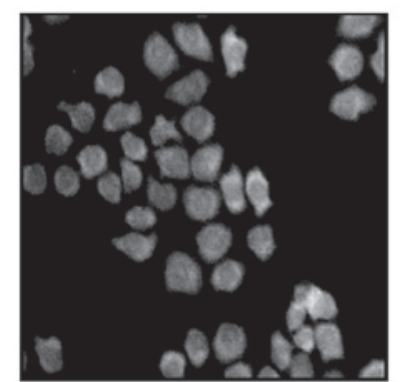

B

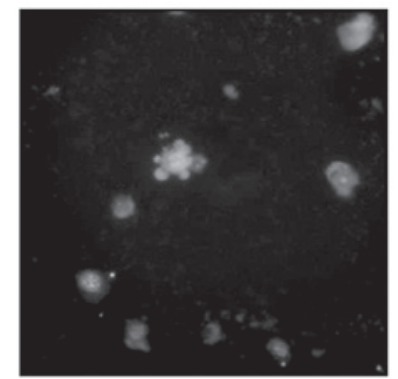

C

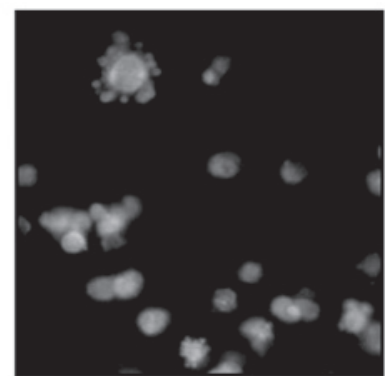

D

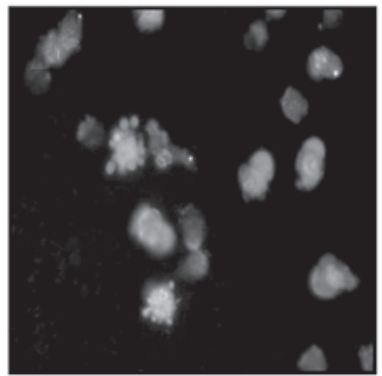

$\mathbf{E}$

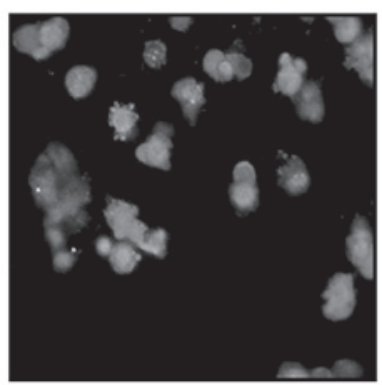

Figure 3. Effect of podophyllotoxin on the morphology of SGC-7901 cells treated with (A) negative control, (B) $13.15 \mu$ mol/1 podophyllotoxin, (C) $26.30 \mu$ mol/1 podophyllotoxin, (D) $52.60 \mu \mathrm{mol} / 1$ podophyllotoxin and (E) $55 \mu \mathrm{mol} / 1 \mathrm{HCPT}$ as a positive control. HCPT, hydroxycamptothecin.

$\mathbf{A}$

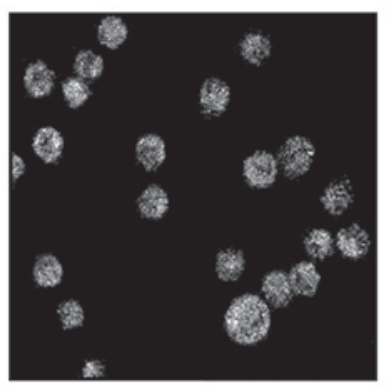

D

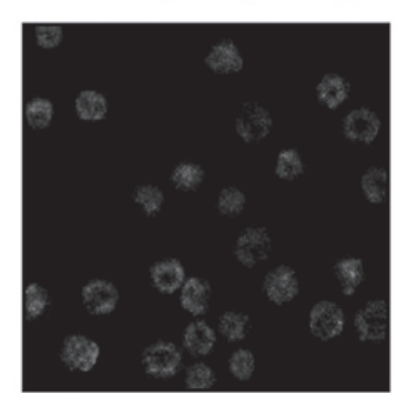

B

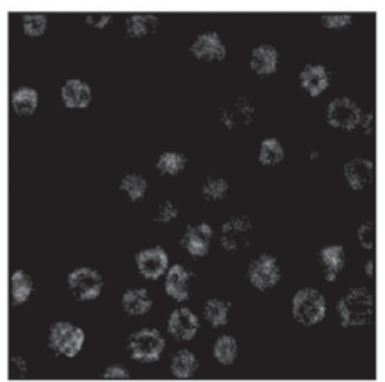

$\mathbf{E}$

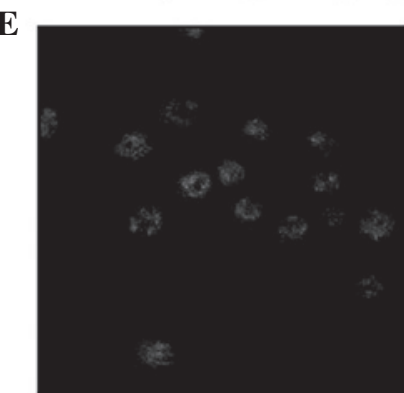

Figure 4. Effect of podophyllotoxin on the MMP in SGC-7901 cells treated with (A) negative control, (B) $13.15 \mu$ mol/1 podophyllotoxin, (C) $26.30 \mu$ mol/1 podophyllotoxin, (D) $52.60 \mu \mathrm{mol} / 1$ podophyllotoxin and (E) $55 \mu \mathrm{mol} / 1 \mathrm{HCPT}$ as a positive control. MMP, inner mitochondrial membrane potential; HCPT, hydroxycamptothecin.

Effect of podophyllotoxin on the morphology of SGC-7901 cells. Under an inverted fluorescence microscope, the cells in the control group were observed to grow normally and the fluorescence in the cell nuclei was uniform. Following treatment with various concentrations of podophyllotoxin for $48 \mathrm{~h}$, a high proportion of cells exhibited apoptosis-like changes, including cell detachment, cytoplasmic condensation and the appearance of apoptotic bodies, in a concentration-dependent manner (Fig. 3).

Effect of podophyllotoxin on the MMP in SGC-7901 cells. Following treatment with various concentrations of podophyllotoxin for $24 \mathrm{~h}$, the fluorescence intensity of Rhodamine 123 in cells decreased, indicating that the level of the MMP had decreased. With increasing drug concentrations, the level of the MMP decreased accordingly and statistically significant differences were observed when compared with the control group $(\mathrm{P}<0.05)$, as shown in Table II and Fig. 4.

Effect of podophyllotoxin on the expression levels of cyt-c, pro-caspase-9,pro-caspase-3 and caspase-3 in SGC-7901 cells. Following treatment with various concentrations of podophyllotoxin for $24 \mathrm{~h}$, the expression levels of apoptosis-related proteins in SGC-7901 cells changed. The expression level of cyt- $c$ increased, while the expression levels of pro-caspase- 9 and pro-caspase- 3 decreased in a concentration-dependent 
A
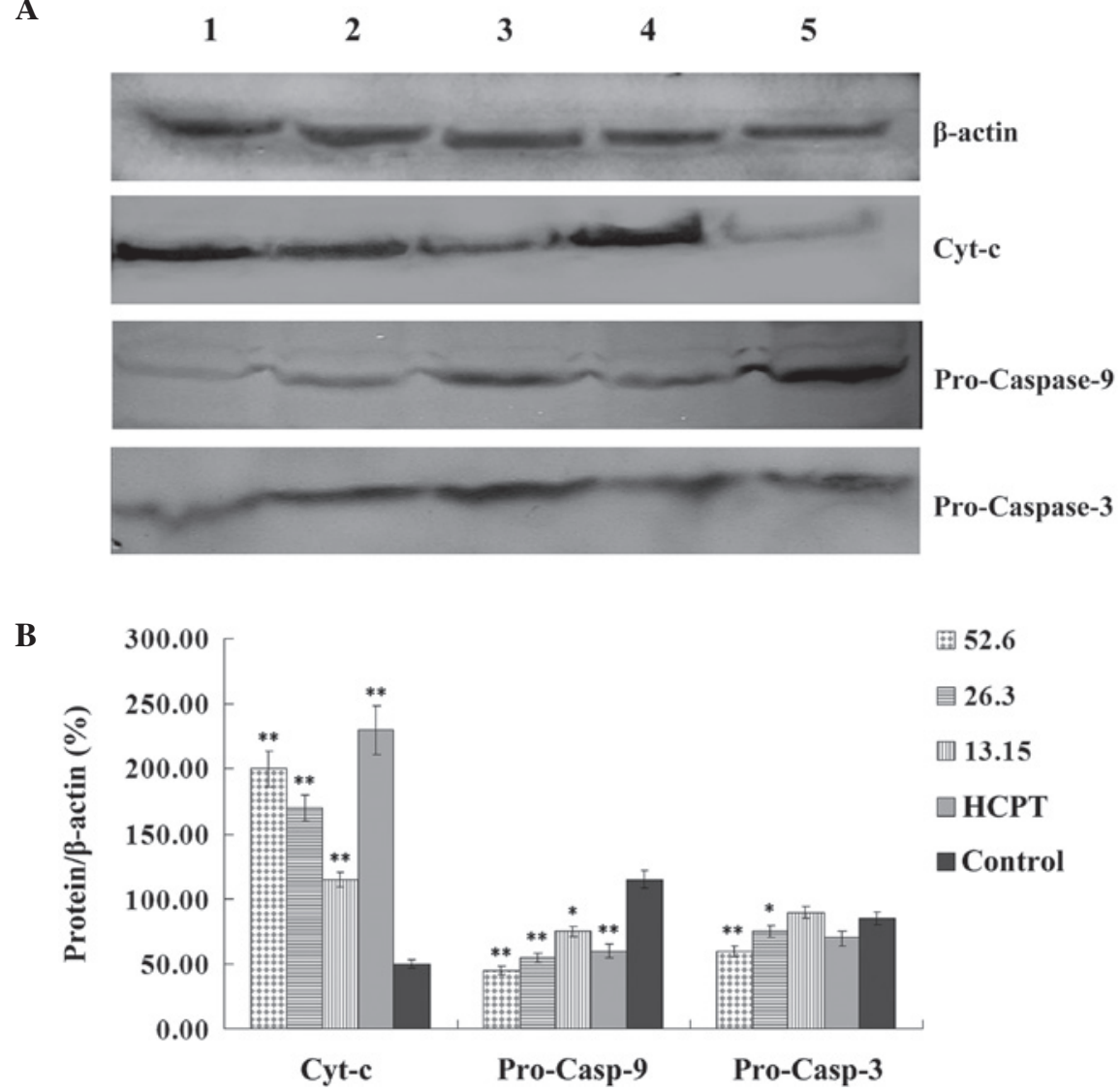

Figure 5. (A) Representative blot and (B) quantitative results demonstrating the effect of podophyllotoxin on apoptosis-related proteins in SGC-7901 cells treated with: Lane 1, $52.60 \mu \mathrm{mol} / 1$ podophyllotoxin; lane 2, $26.30 \mu \mathrm{mol} / 1$ podophyllotoxin; lane 3, $13.15 \mu \mathrm{mol} / 1$ podophyllotoxin; lane $4,55 \mu \mathrm{mol} / 1 \mathrm{HCPT}$ (positive control); and lane 5, negative control. HCPT, hydroxycamptothecin.

Table II. Effect of podophyllotoxin on MMP in SGC-7901 cells (20 wells).

\begin{tabular}{lcc}
\hline Group & $\begin{array}{c}\text { Concentration } \\
(\mu \mathrm{mol} / \mathrm{l})\end{array}$ & $\begin{array}{c}\text { Mean fluorescence } \\
\text { intensity }\end{array}$ \\
\hline Control & 0.00 & $64.13 \pm 4.22$ \\
Podophyllotoxin & 26.30 & $28.37 \pm 7.85^{\mathrm{b}}$ \\
& 52.60 & $20.17 \pm 4.06^{\mathrm{b}}$ \\
HCPT & 55.00 & $27.55 \pm 9.16^{\mathrm{b}}$ \\
& 13.15 & $44.80 \pm 1.97^{\mathrm{b}}$ \\
\hline
\end{tabular}

Values are expressed as the mean $\pm \mathrm{SD}$. ${ }^{\mathrm{a}} \mathrm{P}<0.05$, vs. control. ${ }^{\mathrm{b}} \mathrm{P}<0.01$, vs. control. HCPT, hydroxycamptothecin; MMP, inner mitochondrial membrane potential.

manner. Statistically significant differences were observed when compared with the control group $(\mathrm{P}<0.05)$, as shown in Fig. 5 .

\section{Discussion}

Apoptosis is a rigorous, active and orderly process of cell death that is regulated by numerous genes in order to maintain the stability of the intracellular environment. The mitochondrial pathway is one of three major apoptotic pathways. This pathway involves the induction of apoptosis factors, the life-or-death apoptosis switch, the start molecules of apoptosis (cyt-c) and the effector molecules of apoptosis, including caspase-9 and caspase-3.

A change in the permeability of the mitochondrial membrane is the most significant event in apoptosis and this permeability is controlled by the mitochondrial permeability transition pore (MPTP), which is the key to the apoptotic mitochondrial pathway (10). The MMP is a result of the asymmetric distribution of protons and other ions across the inner membrane of the mitochondrion, and is necessary for sustaining mitochondrion function. The MMP is one of the best indicators of mitochondrion permeability (11). In the present study, the fluorescent probe Rhodamine 123 was used for staining. The experimental results demonstrated that following the treatment of SGC-7901 cells with podophyllotoxin for $24 \mathrm{~h}$, the MPTP channels opened, the MMP decreased and the permeability of the mitochondrial membrane increased, resulting in irreversible cell apoptosis.

The release of cyt- $c$ occurs in the early stages of cell apoptosis (12). Cyt- $c$ is released into the cytoplasm through mitochondrial outer membrane permeabilization, which is regulated by MPTP or members of the Bcl-2 family. The release of cyt- $c$ results in the activation of caspases. Caspases are a type of proenzyme that, under normal conditions, contain no reactive site. In caspase-dependent mitochondrial pathways, cyt- $c$ is released from the mitochondria and interacts with aminophospholipid transferase and apoptotic peptidase activating factor 1 , subsequently converting these molecules to polymers 
and promoting their interaction with caspase-9 to form apoptotic bodies (13). Cyt- $c$ is capable of activating caspase-9 by hydrolyzing its proenzyme, and the activated caspase- 9 further activates caspase-3, leading to cell apoptosis (14). The results of the present study demonstrate that podophyllotoxin facilitates the release of cyt- $c$ from the mitochondrion into the cytoplasm, which decreases the expression levels of pro-caspase- 9 and pro-caspase-3, leading to the caspase cascade with the formation of a caspase-dependent pathway. Therefore, apoptosis is induced in SGC-7901 cells via the mitochondrial pathway.

In conclusion, podophyllotoxin induces apoptosis in the human GC SGC-7901 cell line through the mitochondrial pathway.

\section{Acknowledgements}

The study was supported by a grant from the Program of Natural Science Foundation of Heilongjiang Province (no. QC2011C100).

\section{References}

1. Hu Y, Fang JY and Xiao SD: Can the incidence of gastric cancer be reduced in the new century? J Dig Dis 14: 11-15, 2013.

2. Ji YB, Ji CF and Zhang H: Laminarin induces apoptosis of human colon cancer LOVO cells through a mitochondrial pathway. Molecules 17: 9947-9960, 2012.

3. Ji YB, Ji CF, Yue L and Xu H: Saponins isolated from Asparagus induce apoptosis in human hepatoma cell line HepG2 through a mitochondrial-mediated pathway. Curr Oncol 19 (Suppl 2): eS1-eS9, 2012.

4. Wang B, Chen L, Zhen H, et al: Proteomic changes induced by podophyllotoxin in human cervical carcinoma HeLa cells. Am J Chin Med 41: 163-175, 2013.
5. Yang TM, Qi SN, Zhao N, et al: Induction of apoptosis through caspase-independent or caspase-9-dependent pathway in mouse and human osteosarcoma cells by a new nitroxyl spin-labeled derivative of podophyllotoxin. Apoptosis 18: 727-738, 2013.

6. Rojas-Sepúlveda AM, Mendieta-Serrana M, Mojica MY, et al: Cytotoxic podophyllotoxin type-lignans from the steam bark of Bursera fagaroides var. fagaroides. Molecules 17: 9506-9519, 2012.

7. Xu H,Lv M and Tian X: A review on hemisynthesis, biosynthesis, biological activities, mode of action, and structure-activity relationship of podophyllotoxins: 2003-2007. Curr Med Chem 16: 327-349, 2009.

8. Hartmann JT and Lipp HP: Camptothecin and podophyllotoxin derivatives: inhibitors of topoisomerase I and II - mechanisms of action, pharmacokinetics and toxicity profile. Drug Saf 29: 209-230, 2006

9. Zhang J, Zhou CS, Liu S, Chen H and Yang C: Effect of podophyllotoxin on human gastric cancer cell line SGC 7901. Zhong Nan Da Xue Xue Bao Yi Xue Ban 33: 718-722, 2008 (In Chinese).

10. Martin LJ: The mitochondrial permeability transition pore: a molecular target for amyotrophic lateral sclerosis therapy. Biochim Biophys Acta 1802: 186-197, 2010.

11. Lemeshko VV: Potential-dependent membrane permeabilization and mitochondrial aggregation caused by anticancer polyarginine-KLA peptides. Arch Biochem Biophys 493: 213-220, 2010

12. Scorrano L: Opening the doors to cytochrome c: changes in mitochondrial shape and apoptosis. Int J Biochem Cell Biol 41: $1875-1883,2010$.

13. dos Santos AB, Dorta DJ, Pestana CR, et al: Dehydromonocrotaline induces cyclosporine A-insensitive mitochondrial permeability transition/cytochrome c release. Toxicon 54: 16-22, 2009.

14. Lee HJ, Lee HJ, Lee EO, et al: Mitochondria-cytochrome c caspase-9 cascade mediates isorhamnetin-induced apoptosis. Cancer Lett 270: 342-353, 2008. 